\title{
Evaluation of Antibacterial Activity of Laccase from Bacillus subtilis
}

\author{
R. Ambily", M. Kour, M. Shynu, B. Bhatia and T. V. Aravindakshan \\ School of Applied Animal Production and Biotechnology, College of Veterinary and Animal \\ Science, Mannuthy, Thrissur, Kerala-680 651, India \\ *Corresponding author
}

\section{A B S T R A C T}

\begin{tabular}{l} 
Key w o r d s \\
$\begin{array}{l}\text { Laccase, } \\
\text { Bacillus subtilis, } \\
\text { Antibacterial }\end{array}$ \\
Article Info \\
$\begin{array}{l}\text { Accepted: } \\
\text { 26 April } 2020 \\
\text { Available Online: } \\
\text { 10 May } 2020\end{array}$ \\
\hline
\end{tabular}

The study was undertaken to evaluate the antibacterial activity of laccase from Bacillus subtilis. Laccase was extracted using rice bran as substrate and analysed using guaiacol. Anti-bacterial activity against Escherichia coli and Staphylococcus aureus was assessed by broth microdilution employing direct colony suspension method. Laccase was found to inhibit the growth of E. coli. However, no antibacterial activity could be observed against Staphylococcus aureus. Hence, laccase cannot be considered as an effective broad spectrum antibacterial agent. Since the antibacterial potential is proved, its activity in combination with other antimicrobial agents may be evaluated.

\section{Introduction}

Laccase is an enzyme that belongs to the group oxidases and a member of multi blue copper protein family. They were proved to have various biotechnological applications due to their wide substrate specificity and large reaction capabilities.

They are ubiquitous and are distributed in plants and fungi (Benfield et al., 1964) as well as in bacteria (Muthukumaraswamy et al., 2015). Bacterial laccases are highly thermostable and have high production rate. Nevertheless, their role as antibacterial agents had not been studied extensively.

Hence, a study was designed to extract laccase enzyme from the bacteria, Bacillus subtilis which had been demonstrated as an efficient laccase producer (Muthukumaraswamy et al., 2015) and to evaluate their antibacterial activity. 


\section{Materials and Methods}

The type culture of Bacillus subtilis MTCC 2414 was procured from Microbial Type Culture Collection (MTCC), Chandigarh. The production of laccase from the bacteria was done as per Muthukumaraswamy et al., (2015). Rice bran (50g) was procured from local market and washed two times with distilled water and boiled for $15 \mathrm{~min}$. The water was then decanted and dried in an oven at $60^{\circ} \mathrm{C}$ and powdered and stored at room temperature. To $50 \mathrm{~mL}$ Mineral Basal Salt Solution (MBSS) prepared using peptone $(3 \mathrm{~g} / \mathrm{L})$, dextrose $(10 \mathrm{~g} / \mathrm{L})$, dipotassium hydrogen phosphate $(0.4 \mathrm{~g} / \mathrm{L})$, potassium dihydrogen phosphate $(0.6 \mathrm{~g} / \mathrm{L})$, manganese sulphate $(0.5 \mathrm{~g} / \mathrm{L})$, ferrous sulphate $(0.0005$ $\mathrm{g} / \mathrm{L})$ and Zinc sulphate $(0.01 \mathrm{~g} / \mathrm{L}), 2 \mathrm{~g}$ of rice bran with peptone (three per cent) was added. This was sterilised, cooled to room temperature and added sterile sucrose (three per cent). This was inoculated with $3.5 \times$ $10^{6} \mathrm{CFU}$ of B. subtilis and incubated at $30^{\circ} \mathrm{C}$ for $24 \mathrm{~h}$. After incubation, the contents were mixed thoroughly with $50 \mathrm{mM}$ glycine- $\mathrm{NaOH}$ buffer ( $\mathrm{pH}$ 9.0) under shaking. The contents of the flasks were centrifuged at $10000 \mathrm{rpm}$ for $10 \mathrm{~min}$. at $4^{\circ} \mathrm{C}$. After centrifugation, the supernatant was collected and concentrated by fractioned precipitation using 80 per cent ammonium sulphate saturation. This was dialysed against $50 \mathrm{mM}$ phosphate buffer $(\mathrm{pH}$ 8.0) and analysed by SDS-PAGE using 12 per cent polyacrylamide gel. The extract obtained was streaked on Luria Bertani agar containing 0.1 per cent guaiacol followed by incubation at $30^{\circ} \mathrm{C}$ for $12 \mathrm{~h}$ for confirmation of laccase activity and was used for further studies.

The antibacterial potential of the laccase was tested against the type cultures of Escherichia coli and Staphylococcus aureus procured from MTCC, Chandigarh by microdilution method using direct colony suspension method as per CLSI guidelines (CLSI, 2018).
The inocula of E. coli and S. aureus were prepared by making broth suspension of isolated colonies from 18- 24 hour agar plate in brain heart infusion agar (BHIA). The turbidity of the inocula was adjusted to that of 0.5 McFarland standard using BHI broth. A volume of $150 \mu \mathrm{l} \mathrm{BHI}$ broth was taken in the first seven wells of rows A and B of microtitre plate. About $150 \mu 1$ of extracted laccase containing $1.1 \mathrm{mg}$ protein was added to $150 \mu 1 \mathrm{BHI}$ broth in well 1 of row A. Mixed and transferred $150 \mu 1$ to the next well. This was serially diluted till the $7^{\text {th }}$ well from which $150 \mu 1$ was discarded. In row $B$, control was set in the same manner using ampicillin suspension. The $8^{\text {th }}$ well of both the rows contained $150 \mu \mathrm{l}$ broth culture of E. coli. In the $9^{\text {th }}$ well, broth alone was added. Then $5 \mu 1$ containing about $5 \times 10^{5}$ cells of $E$. coli was added to all the wells and incubated at $37^{\circ} \mathrm{C}$ overnight. The whole procedure was repeated with S. aureus inoculum. Minimum Inhibitory Concentration (MIC) is the lowest concentration of antimicrobial agent that completely inhibits growth of organism in micro dilution wells as detected by unaided eye. For a test to be valid, $\geq 2 \mathrm{~mm}$ button/ definite turbidity in control well without antibiotic should be there $\geq 80 \%$ reduction in growth as compared to control is the end point.

\section{Results and Discussion}

The study involves evaluation of antibacterial activity of laccase extracted from B. subtilis using rice bran as substrate. Agroresidues like rice bran and wheat bran were proved to be good substrates for extraction of laccase from bacteria (Chawachart et al., 2004; Muthukumaraswamy et al., 2015). The presence of protein with molecular weight 55 $\mathrm{kDa}$ was confirmed by SDS-PAGE. In order to analyse laccase activity, guaiacol was used as substrate and brown coloured zone formed in plate assay due to the oxidation of substrate 
confirmed laccase activity. There are reports of laccase acting as a catalyst in bactericidal action of chitosan- gallic acid derivative against E. coli and Staphylococcus aureus $(\mathrm{Li}$ et al., 2019). However, the antibacterial activity of laccase against these organisms has not been demonstrated so far.

This study revealed antibacterial activity of laccase extracted from $B$. subtilis against $E$. coli, at a concentration of $1.1 \mathrm{mg}$. It was found that in the plate inoculated with E. coli, only the first well of row A, i.e. well containing laccase showed more than 80 per cent reduction in growth. Row B, i.e. control with ampicillin suspension exhibited inhibition of growth in all the wells. In the eighth well i.e. control well without laccase or ampicillin, turbidity indicating bacterial growth could be observed. In the microtitre plate inoculated with $S$. aureus, more than 80 per cent reduction in growth could not be observed in any of the wells of row A. No antibacterial activity could be observed against Staphylococcus aureus since growth was observed in all the wells even at high concentration of laccase (Fig. 1).

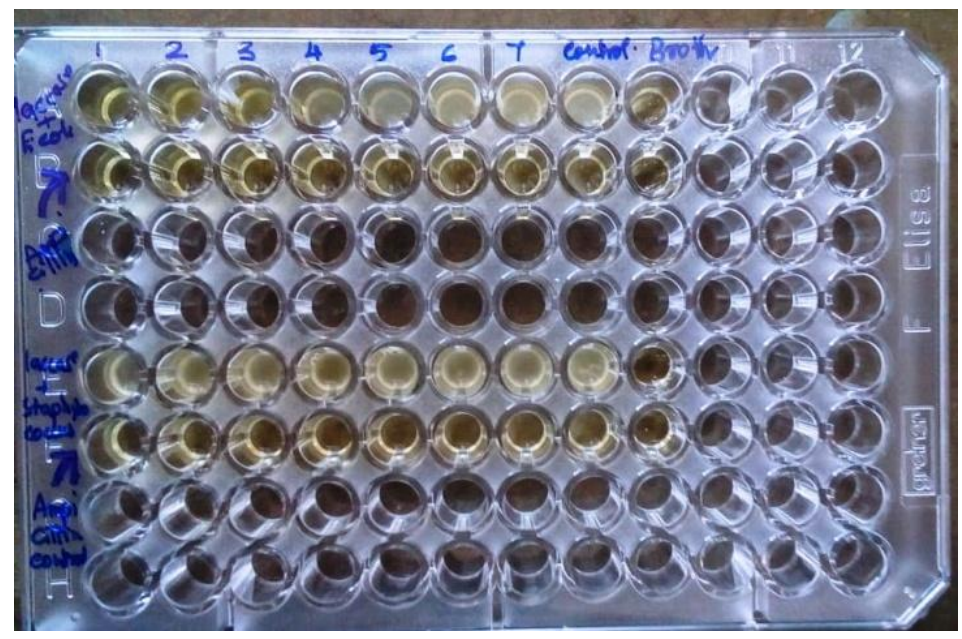

Fig.1 Antibacterial activity of laccase

Row A; Columns 1-7- Laccase + E. coli

Row A; Columns 8 - E. coli broth culture without laccase

Row A; Columns 9 - Broth alone

Row B - Ampicillin + E. coli

Row E; Columns 1-7- Laccase + S. aureus

Row E; Columns 8 - S. aureus broth culture without laccase

Row E; Columns 9 - Broth alone

Row F- Ampicillin + S. aureus

Thus, it can be concluded that laccase as such could not be recommended as an antibacterial agent. However, the antibacterial activity was proved against Gram negative bacteria, E. coli and hence, further study to standardise the procedures to explore its utility in reducing the burden of indiscriminate antibiotic usage is recommended. The analysis of the efficacy of laccase in combination with other antibacterial agents so as to reduce the concentration of them is also suggested.

\section{References}

Benfield, G., Bocks, S.M., Bromley, K. and Brown, B.R. 1964. Studies in fungal and plant laccases. Phytochem. 3: 7988. 
Chawachart, N., Khanongnuch, C., Watanabe, T. and S. Lumyong. 2004. Rice bran as an efficient substrate for laccase production from thermotolerant basidiomycete Coriolus ersicolor strain RC3. Fungal Diversity. 15: 23-32.

Clinical and Laboratory Standards Institute. 2018. Performance standards for antimicrobial susceptibility testing; $28^{\text {th }}$ international supplement M100-S21. Wayne, PA: CLSI.

Li, K., Guan, G., Zhu, J., Wu, H. and Sun, Q.
2019. Antibacterial activity and mechanism of a laccase-catalyzed chitosan-gallic acid derivative against Escherichia coli and Staphylococcus aureus. Food Control. 96: 234-243.

Muthukumarasamy, N. P., Jackson, B., Raj, A. J. and Sevanan, M. 2015. Production of extracellular laccase from Bacillus subtilis MTCC 2414 using agroresidues as potential substrate. Biochem. Res. Internatl. 2015: 1-9.

\section{How to cite this article:}

Ambily, R., M. Kour, M. Shynu, B. Bhatia and Aravindakshan, T. V. 2020. Evaluation of Antibacterial Activity of Laccase from Bacillus subtilis. Int.J.Curr.Microbiol.App.Sci. 9(05): 2960-2963. doi: https://doi.org/10.20546/ijcmas.2020.905.351 